\title{
Decreased Therapeutic Response
}

National Cancer Institute

\section{Source}

National Cancer Institute. Decreased Therapeutic Response. NCI Thesaurus. Code C50526.

A reduction in the desirable and beneficial effects resulting from a medical treatment. 